\title{
Investigation and Analysis of the Current Situation of Extracurricular English Learning for Contemporary Medical Majors
}

\author{
Yuan Kong* \\ School of Foreign Languages \\ Jining Medical University \\ Jining, China \\ kongy_1116@163.com
}

\author{
Guisong Yang \\ School of Clinical Medicine \\ Jining Medical University \\ Jining, China
}

\begin{abstract}
In order to understand the current status of extracurricular English learning for medical students, this article investigates the status of extracurricular English learning for medical students in several medical colleges in Shandong Province. This study uses an online questionnaire as the main form and starts with learning methods, learning objectives, learning status, and understanding of learning. Investigating and analyzing the extracurricular English learning methods and actual conditions of medical college students. The survey shows that although the contemporary medical students have a strong emphas is on English, they are passive in learning. They lack of subjective interest, have the ability to study independently, lack of the scientific and effective arrangement and have the characteristics of "relative independence". Then, it comes up with the idea of "building an English environment" and so on, which provides the guidance and advice for the students how to conduct effective English learning.
\end{abstract}

Keywords-contemporary medical majors; extracurricular English learning methods; relative independence; English environment; analysis

\section{INTRODUCTION}

With the development of the times, all kinds of industries are making continuous progress, the exchange of experience is very important, and medicine as a practical discipline is at the forefront. With the rapid development of globalization, traditional knowledge is not enough to meet the need and the international exchange of medical science and technology experience is booming. As an international language, English must be familiar to medical workers. Medical students, as the reserve of medical talents in the future, want to keep up with the pace of development; they must constantly improve

This paper is sponsored by A Project of Shandong Province Higher Educational Humanities and Social Sciences Research (J17RA054); Social Science Planning Research Program of Shandong Province (17CWZJ38); College Students' Innovative Training Project of Jining Medical University (cx2017052); Scientific Research Project of College Students in Jining Medical University (JYXS2017RW017); Research Program of Young Teachers' Education and Teaching of Shandong Province (16SDJ232); Youth and Adolescents Quality Education Work Planning Program of Shandong Province (13AJY090); Scientific Research Program of Jining Medical University (JY2013RW032); The Visiting Scholar Funded Program of Young Backbone Teachers in Jining Medical University; An Industry-University Cooperative Project of Ministry of Education.

$\square$ Corresponding author: Yuan Kong, Email: kongy_1116@163.com themselves and keep abreast of the latest trends of research results at home and abroad. Consult foreign literature and exchange experience with advanced workers at home and abroad. Learning and using English should be more basic skills. Therefore, there is no doubt about the importance of English learning for medical students.

"Extracurricular learning", outside of class, is similar to the "autonomous learning"[1]. Extracurricular learning includes spontaneous and non spontaneous, direct and indirect, different forms of learning, all non classroom accommodation and the ability to improve English ability. As a language subject, English requires a long period of accumulation, a lot of practice. It can not achieve its goal by only relying the short classroom on time but requires students to complete their autonomous learning outside the classroom. From the particularity of language learning, the success or failure of foreign language learning depends to some extent on the quality of extracurricular learning. The Requirements of College English Course (2007) also pointed out: "according to the actual situation, we should draw up the syllabus to guide the teaching of college English." Moreover, it is expounded that students' autonomous ability of learning should be enhanced."[3] Therefore, we should understand the extracurricular English and enhance them to master learning methods of medical major students. The present situation is of great significance to help to fundamentally improve the English proficiency of college students.

\section{RESEARCH DESIGN}

This survey adopts the form of network questionnaire, taking several undergraduate colleges in Shandong Province as the object of investigation, using questionnaire star as the platform of network to answer paper, distributing and putting in through the teacher's assistance and students' relationship, and the MB volunteer to answer the questions. According to the needs of the research and the actual situation, the questionnaire is designed by the author with reference to the relevant literature and some scholars. The questionnaire is divided into four parts, which conclude student information, learning status, evaluation recommendations and free answers. The questionnaire selection is divided into two categories: "directed selection", in which only one of the respondents can 
be selected, and "indefinite choice", in which the respondents can type in one of the answers they approve. The fourth part of the question and answer question is expressed freely by the subjects.

The time of this investigation is 180 days, a total of 529 students have completed the questionnaire, of which 513 valid questionnaires, and the effective rate is $97.0 \%$, in which the freshman students accounted for $31.77 \%$. The sophomore students accounted for 45.8 percent, the other grades accounted for $22.5 \%$. The ratio between men and women is $4: 6$. The survey data are analyzed by SPSS 2.0. The data are presented in the form of number and percentage (rounding) in this paper.

\section{DATA ANALYSIS}

\section{A. Learning motivation}

\section{1) Importance}

According to the data obtained, medical students' understanding of the importance of English learning is relatively uniform. 93.2\% of medical students think that English learning is very important and 5.3\% think that English learning is very important, while only $0.2 \%$ think that English learning is not important. It can be said that a large number of medical students attach great importance to English learning.

\section{2) Learning motivation}

According to the data from the survey of learning motivation, the students who really like English are relatively few, accounting for $9.4 \%$. Compared with the similar research results of other domestic scholars, it is not difficult to find that a few of the students of almost all kinds of professional college students in the country regard their interest in English as the motivation for learning and lack of initiation in learning. And $72.5 \%$ of medical students chose to get a degree in order to pass various examinations. This special major in clinical practice has special requirements for English proficiency: that is, if the degree certificate is linked to the CET-4 certificate, students will not be able to graduate if they do not reach the CET-4 level, although this is the motivation for students to learn English on the one hand. But it will make students' English study as a task, and it will be easier to develop fear over time, thus losing their original interest. But on the other hand, students' initiation and self-improvement are improved. The data shows that $75.0 \%$ of the students have chosen 'to adapt to social development and personal needs", indicating that medical students have already understood the meaning of English proficiency to themselves, although few students have a real interest. The data also shows good signs that students are becoming responsible for their own learning and do not need to be instilled in. That is learner autonomy (learner autonomy) [4]. In addition, according to the results of the survey, $24.6 \%$ of the students chose 'to study abroad" and $18.9 \%$ chose "to understand foreign culture." this seems to indicate that many of the medical students are full of thirst for foreign culture and expect to broaden their horizons. Contact the world and learn more. And nearly half of the students chose 'to communicate with foreigners", indicating that medical students' interest in learning is growing.
To sum up: medical students have realized the importance of learning English as far as learning motivation is concerned. Although the intrinsic interest in learning English is still very low, with the development of social culture, the desire of many students to improve their self-comprehensive qualities is also increasing. It can be said that most students have their own purpose of learning, and even some students have developed their own potential interests. To produce pleasant autonomous learning, this suggests that the desire to learn from the heart seems to be more motivating, and that this desire is more comfortable and satisfying to one's own needs. So if a teacher is in the process of teaching, By grasping the motivation to promote students' learning and cultivating students' interest in various aspects, it is more possible for students to integrate into learning, so that more students have their own learning motivation and become willing to active spontaneous learning.

\section{B. Status of learning}

\section{1) Learning Arrangement}

Investigation finds that the extracurricular learning arrangements of students are not optimistic. The results showed that $66.0 \%$ of the students did not make their own study plan,. It was found that more than half of the students tended to surprise themselves before the exam without actively planning their study time. Furthermore, it can be found that a large proportion of students have casual extracurricular study hours and short periods of time, most of which are less than 30 minutes. Although medical students have recognized the importance of English, as far as the above results are concerned. in actual learning life, they are not able to organize their own and reasonable learning plans, and it is only in the examination before the temporary assault. Usually extracurricular English learning time is short and casual. In terms of the particularity of language, the extracurricular learning time of students is particularly important, but according to the data of the survey results, the ability for students to arrange their learning time autonomously is still generally poor.

From the results of the survey, we can see that $73.86 \%$ of the people are afraid of being nervous and lack of confidence, $71.49 \%$ of the people are due to the lack of opportunities to practice spoken English, and $43.86 \%$ of the people are due to lack of vocabulary and poor pronunciation and intonation. $49.56 \%$ of the people were unable to make words into sentences because of their weak grammar. It can be seen that lack of self-confidence is also an important factor hindering the expression of English. Therefore, teachers should give more encouragement to students in their study and life, and should not be reluctant to speak because they do not express their lack of confidence. The more we should say no, Well, the more we practice and express ourselves, the more progress we can make only when we overcome our challenges. The other is the students' self-factors, the lack of vocabulary or grammatical ability, for these teachers should first encourage them to learn to solve their own problems. Then, check the gaps to avoid individual student shortcuts. There is also a lack of communication that leads to a lack of language experience. Teachers should provide students with a good environment for 
language exchange, Let students communicate more; improve the use of English opportunities.

\section{2) Learning styles}

A study of the methods commonly used in extracurricular English Learning for Medical College students. It can be found that the most dominant way to learn English is to use books to memorize the word, which is commonly referred to as "memorizing words." According to the results, 92.6\% of the students chose this item, and the proportion of choice was quite high. In addition, "reciting examples, short essays" the selection rate is as high as $80.3 \%$. However, the selection rate of "cooperating with friends" in the learning style is only $18.5 \%$. This proves that autonomous learning for medical students' English has a great "relative independence" [5]. Thus it can be seen that "memory" is still the most commonly used by medical students.

In addition, according to the findings: "watching English movies, TV dramas, varieties shows" and "listening to English songs" are also popular among college students. The proportion of choice reached $76.6 \%$ and $73.9 \%$ respectively, which showed that in addition to the traditional learning methods, medical students are more inclined to choose relaxed and pleasant learning means, which is also in line with the nature of human entertainment. 'Reading English newspapers, books", which are also exposed to foreign cultures, has a relatively low selection rate, probably because reading English articles is relatively difficult and more difficult for students with low English proficiency. Another point is that the learning method is less entertaining, slightly dull, and not easy to be welcomed by students. The choice rate of "watching English news and listening to English radio station" also shows this point, which is only $18.5 \%$.

For the contents related to English classroom teaching, "doing English exercises" has the highest selection rate (61.4\%), followed by "reviewing the content of teaching materials" $(38.0 \%)$. The formation of this result is related to the present teaching methods, in which "English examination" promotes students' preference for doing English exercises. However, English problems are different from other subjects in assessing students' vocabulary mastery and reading ability. However, as for students, in order to cope with the present examination way, therefore that is more tend to "recite examples, short essays". It is also worth mentioning that the number of people who chose "Learning Grammar Book" is only $37.20 \%$. This is also related to the change of English examination style to focus on reading ability. In addition, the proportion of students who choose "ask a question from a teacher" is only $36.6 \%$, which shows that the communication between medical students and English teachers is not close, which is also related to the "relative independence" of study. Therefore, teachers should pay attention to the cultivation of communication with students, pay attention to improve the feelings of teachers and students, draw closer distance, and encourage students to actively consult, so as to improve teaching efficiency.

In addition, there are several new forms of English learning: "using mobile app to learn", "watching online courses" and "watching online courses" account for $17.3 \%$. For another, "participating in English community" accounts for 11. 1\%, the selection rate of "using mobile phone app to learn" is higher. This shows that these new learning methods have possibility to become the mainstream of future English learning.

Furthermore, it can be found that "writing English articles" and "attending tutoring classes" are the lowest or even less than $10 \%$, which shows that these two learning methods are not very popular among medical students.

On the basis of the above data analysis, we can draw a conclusion that the English extracurricular learning style of medical college students mainly depends on the traditional "memory", and the learning has the "relative independence" of the choice of learning methods. Students tend to be more relaxed and easy to learn, at present, the new learning methods related to network media have not been accepted by the vast number of students that the English learning of medical students has "relative independence", and students prefer to carry out extracurricular study independently.

\section{On student self-evaluation and goal expectations}

We carried out a survey of the medical students' English proficiency. The analysis of the data obtained shows that Pearson's deviation is less than 0 , which indicates that medical students' English level is optimistic, but some students' English level is still in poor condition. The importance of English is well known. It is the fundamental responsibility of English education to help every college student to improve his English performance.

The results of the survey on whether college students' English proficiency has improved since college are surprising. With 75.9 percent of students said that they had not improved their English after coming into college. And we predict a large proportion of the "big improvement" of only 2.5 percent, which suggests that many students still use the knowledge they had before the college entrance exam. This may have something to do with the ethos of learning in universities, but the findings are surprising. However, according to the previous findings, students' ability to arrange their own learning time is generally poor. So such results should be expected. In view of this, we can draw a conclusion: medical students' progress in college English learning is poor.

A survey of the public activities shows that college students wish to carry out in order to improve their English proficiency. Although the forms chosen are different, it can be found by comparison and combining with the previous conclusions. Medical students seem to have a special interest in English movies, which has something to do with film as a form of recreation and entertainment. Medical students tend to study in a relaxed and happy way. In addition, according to the survey data, schools can also actively carry out activities according to the actual situation to encourage students to learn diversity.

We can provide appropriate activities and games to provide a platform for students to show themselves, so that not only can the students enjoy themselves, but also exercise them and improve their English. And most of the students are very satisfied with the extracurricular activities organized by the College English Department. They expect these activities to be 
held, because they provide the students with the opportunity to communicate, and they also provide the students with a platform for showing themselves. It increases the students' selfconfidence and stimulates the students' enthusiasm for learning.

\section{Free Answer}

Combined with the purpose of this study, the author chooses "dear, in the extracurricular English learning, do you have any good ways and means to share with me?" as a question. This question got 127 answers, excluded some meaningless answers, the author summarized the answers: Recommended learning software such as word chopping, fluent, Kingsoft, English dubbing or WeChat public name for example keins, recommended radio station such as litchi FM, suggested listening to English songs, trying to block subtitles to watch English movies, watching BBC, summarized learning methods such as boldly communicating with others, making foreign pen pals and so on.

\section{SUMMARY AND RECOMMENDATIONS}

To sum up, we can draw some conclusions and suggestions on extracurricular English learning methods for medical college students.

1) Attach great importance to English, but passive learning purpose, lack of subjective interest.

Modern medical students are no longer ignorant students in ivory tower; they have understood the importance of learning, set up a sense of autonomous learning. However, the study for the purpose of examination makes English learning take become the nature of task, makes students learn under pressure, passively accepts knowledge, and suppresses students' interest [6].

After learning about some students with better academic performance, we have found that most of these students are relatively relaxed in their study, and that they are all interested in the pursuit of knowledge. Do not feel that learning is a very hard and tired thing. This finding also illustrates the fact that if the students are to achieve the good academic results, they must set up correct ideas and regard learning as a need rather than a burden in life.

2) The ability of autonomous learning is general and lacks scientific active and effective arrangement.

Students can not have their own scientific and effective learning plan, or can not adhere to the plan to complete their own learning tasks, is a criticism of contemporary college students. Teachers need to guide, supervise and help college students to complete their English learning tasks.

There are two suggestions for guiding students to learn.

(1)According to the actual situation of local schools, the auxiliary arrangement of extracurricular learning tasks is reasonable.

(2)That is important to adhere to cultivate students' habit of learning according to plan. English study cannot be interrupted; it is called "one day does not practice, 10 days empty". Constantly learning and memory will produce long-term memory, good habit once nurtured, Will benefit a lifetime.
3) The learning style is mainly memorization and relatively independent, so English environment should be established.

The results show that most of the extracurricular English learning methods of contemporary college students are still traditional, and the new English learning methods, which rely on the memorization and recitation of books through the Internet and smart phones, have not yet formed the mainstream trend. Of course, the memory of words is the basis of English, and reciting the text is also a great way to practice English, such as impressive excellent example sentences, a change of words becomes their own sentence. And that can form a good sense of language. However, pure recitation is too dull and boring. Born in a quiet environment, without communication and practice, this learning style is independent [7], which known as "relative independence".

In addition, Chinese students usually have fewer opportunities to speak English, and they all communicate in Chinese because they are not in a foreign context, or because they are afraid of speaking wrong or being seen as a maverick. A big interactive environment for English speaking needs to be built by English teachers. Teachers should create situations to encourage students to engage in dialogue and practice with their classmates, and tell students not to be afraid to speak wrong. Exercise is a chance to correct a mistake. Once an English-speaking environment like this is established [8], English is no longer a boring character in textbooks, but a part of students' life, and the improvement of students' English grades will be easy.

4) For a variety of extracurricular learning methods, students tend to choose a relaxed and enjoyable way that conforms to the interests of teenagers.

Entertainment is nature of every one and it is reasonable for young college students to prefer to choose a relaxed and pleasant way of learning [9]. Teachers can choose pleasant learning methods in the teaching process. Such as English thematic competitions: singing competitions, film dubbing, or holding activities are related to English, such as English corner, English salon, in order to stimulate students' interest in learning.

5) Teaching should expand students' knowledge and meet the actual needs of students

According to the real condition of employment market and the entrance exam for postgraduate, English teaching of medical college must demand acutely students with comparison to other subjects' students. Because the most advanced medicine in the world located in western country, so as to learn fantastic professional knowledge, it needs medical students to obtain excellent English ability. In the meanwhile, the teacher also makes teaching content contact with students' professional knowledge. Only in this way can students understand the real meaning of English learning in the course of gradual teaching. And students can adapt to the development of society as soon as possible [10]. Therefore, the content of college English teaching should be more abundant, which can meet the actual needs of students, improve their interest in learning, and enable students to learn from passive to active. Besides, it is necessary to strengthen the combination of theory with practice and extend the teaching content to practice so as 
to students can not only learn the new language but also get more beneficial things in the classroom.

\section{CONCLUSION}

The situation of college students' extracurricular English learning determines the trend of college students' English learning, which should be attached great importance to English educators. This paper makes an investigation on the present situation of extracurricular English learning methods of medical college students. The results of the investigation are analyzed and some suggestions are put forward in the hope that it can be helpful to the research and work for the vast numbers of English educators, provide reference for universities to cultivate high-quality talents, and play an important role in the construction of educational policy in China.

\section{REFERENCES}

[1] H. Holec, Autonomy and Foreign Language Learning, Oxford: Pergamon Press, 1981.

[2] L. N. Wang, Y. Y. Wu, "A study of the intermediary role of Learning Strategies between Learning motivation and English Autonomous Learning". Foreign language Teaching, 2017, No. 3, pp. 74-78.

[3] Department of higher Education, Ministry of Education. Requirements for College English Teaching, Shanghai: Shanghai Foreign language Education Press, 2007.

[4] D. Little, Learner Autonomy 1: Definitions, Issues and Problems, Dublin: Authentik, 1991.

[5] W. Tao, "the relationship between foreign language Learning Burnout and English Autonomous Learning behavior", Modern foreign language, 2017, No. 2, pp. 223-231.

[6] Y. L. Pan, "Strategies and methods of foreign language Learning", Beijing: Foreign language teaching and research Press.

[7] T. T. Lu, "A study of College English Autonomous Learning Model based on flipping classroom", Chinese foreign language, 2016, No. 1, pp. 77-83.

[8] L. David, Methods and Approaches of Autonomous learning, Fuzhou: Fujian education press, 2010, pp.15.

[9] M. X. Chen, J. D. Tan, “The change of students' learning style from the perspective of Constructivism”, Journal of Hunan University of Science and Technology Press (social science edition), 2008, No.4, pp.124-127.

[10] A. L. Sun, "The functions and the system design of network teaching platform of English pronunciation and intonation”, China Modern Education Equipment, 2013, No.23, pp.46-50. 